\title{
Editorial From Governance to Ground
}

Jennifer Lehmann

Co-Editor, Children Australia
Welcome to our first Issue for 2016 which comes to you as the seasons change from summer to autumn and from winter to spring - a time when we move away from extremes of heat or of cold, of flooding or of droughts. In a sense, it is the need for change from the extremes to something more moderate that underpins the topic of this editorial, which I dedicate to those who, despite their expertise and commitment to the delivery of human services, have found themselves unwanted due to management and governance processes. Indeed, this editorial commentary has been inspired by the story of a man who, after more than 30 years of dedicated and innovative work in the not-for-profit (NFP) sector, was declared redundant just prior to Christmas. It is not the particularities of his treatment that are important here, though many were disgusted by the process. Rather, it is the flow-on effects of governance within the managerialist, neoliberal environment that are my concern - especially their impacts on the ground. My commentary is in two parts: the first summarises the changes in our sector over the last 15 to 20 years with which most of you will be very familiar; the second draws attention to the processes that translate into less than optimum conditions for staff and clients.

Those who have had long established careers in the human services sector will have experienced the multiple thrusts of the neoliberal agenda, which emerged in the 1980s with promises to bring greater efficiency, quality and accountability to bear (Anheier \& Kriev, 2014; Maier, Meyer, \& Steinbereithner, 2014; Smyth, 2014). Its corollaries included privatisation and contracting as the platform for delivering health and welfare services (Abramovitz \& Zelnick, 2015), the rise of managerialism (Considine, O'Sullivan, \& Nguyen, 2014; Smith, 2015), accountability regimes (Morris \& Ogden, 2011; Saj, 2013), and risk devolution and aversiveness (Community Council for Australia, 2014). Small organisations were considered inefficient and economies of scale sought by government in a manner that encouraged waves of agency mergers and takeovers across the decades
(Carey \& Riley, 2012). The notion that this has achieved economies of scale is one that could be challenged, I suspect, but that is another story. However, through these processes we have experienced changes to the language used in our organisations, particularly associated with the language of management, of organisational structures and operations, with the for-profit business sector providing the templates for the governance, management and procedures used in the NFP sector (Smyth, 2014). An example is the shift from 'committees of management' to 'boards of directors', and the ease with which we now talk about strategic planning, risk management and product quality.

It's difficult to understand why the welfare sector capitulated to these processes with so little resistance; and even more difficult is locating the evidence to suggest the changes are of benefit to clients. But it was arguably ideology and value priorities, rather than evidence that were the drivers, such that no rational argument would hold ground. The New Public Management (NPM) approach privileges the values long held in the commercial sector, with the promotion of choice and competition held up to be positively linked to service quality. This is, as pointed out by Abramovitz and Zelnick (2015, p. 285), based on 'the model found in standard economics textbooks explaining that human behaviour is motivated by individual self-interest, that consumer choice and competition yield the most efficient

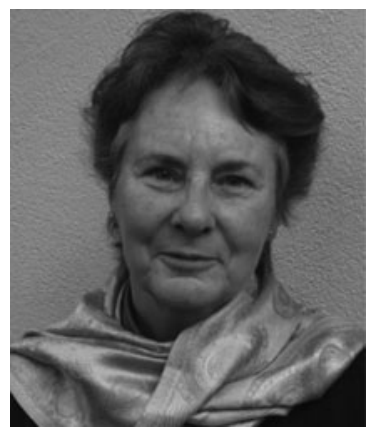


and effective results, and that everything relevant can be quantified'. Implicit are the beliefs that small government is best, individuals are able to take responsibility for themselves, and the systemic environment in which all this takes place is benign. The pressure within the neoliberal environment to cut welfare spending, together with NPM and incomplete funding of services under contractual arrangements (Green, 2012), has intensified, rather than allayed, concerns about NFP financial viability and client wellbeing. Further, Carey and Riley (2012) argue that the choice and competition model for delivering health and welfare services is unlikely to improve health inequalities - and certainly in Australia we are seeing an increasing gap between those with wealth and those in disadvantaged circumstances (Richardson \& Denniss, 2014).

Amalgamations, mergers and takeovers have continued, as have downsizing and reliance on IT and communication technologies, and marketing and branding (Abramovitz \& Zelnick, 2015; Considine, et al., 2014). The shift of power from professional staff delivering services to managers has been a profound change in the NFP sector. The power and status of 'manager' has become an aspiration in itself, perhaps as the managerial language has embedded this aspiration, though some have claimed this is due to a belief that being in such a role will give greater control over undesirable aspects of change - or at least the amelioration of them. Yet, the aspiration to be part of management goes further, with the roles of case worker or social worker becoming 'case manager', the senior social worker or team leader often now named as 'unit or team manager', and programme coordinators becoming 'programme managers'. This trend, incidentally, is not restricted to the human services sector. Similar processes have occurred in some arts organisation - the Australian Ballet, for instance, calls seven of its eleven Philanthropy Team members 'managers', while the remaining members are a Director, an Assistant to the Director and two Coordinators (The Australian Ballet, 2015).

Concurrently, there has also been a steady shift towards appointing managers who do not share disciplinary knowledge or understandings with their staff; and a significant number of managers are qualified in Business Administration/Management, but have never worked on the ground with client groups, nor have a strong grasp of the nature of client work. Such an arrangement brings a different set of values and priorities to the supervision and management of professional staff and this creates additional challenges. Bish and Becker $(2015$, p. 17) investigated NFP management qualities, finding that the required characteristics of NFP managers 'includes self-awareness, strategic thinking, and discipline knowledge, suggest[ing] that in the nonprofit context the manager's own background may be critical'.

The governance of NFPs has shifted too. Boards of governance no longer tend to be chiefly made up of people with shared interests in the wellbeing of their community and/or specific disadvantaged groups; and who promote the agency, carry out fundraising activities and often work alongside staff in organisational development activities. Instead, NPM has stressed keeping governance at arm's length from organisational operations, and on recruiting financial, legal, accounting and economic expertise with a view to supporting the Chief Executive Officer (CEO) and executive staff - and, in some instances, for gaining reputation and networks. In exploring what is meant by 'good governance', Wagner (2014, p.812) comments that there is a tendency for an instrumental understanding of governance to prevail in the NFP sector, in which there is often 'a discrepancy between what is instrumentally effective and [the] morally good', leading to social justice values and goals becoming subservient to economic ones. This is supported by Coule's (2013) research in which she found ' . . if missions, visions, and goals are developed and governed solely by organization elites, it is their perspectives that become prioritized and legitimized at the organization level' (p.88).

In addition, it is not uncommon, in my experience, for CEOs to seek to have board members who will support their ideas and advise, but not challenge. Thus, the relationship of board members to the organisation becomes one based on legal and financial preoccupations that, given the financial platform of the NFP sector, frequently engender anxieties about liabilities and risk (Community Council for Australia, 2014). The board's connection to the work actually undertaken in the agency is often quite remote from staff interactions with clients who are, themselves, often seen as presenting risk. It is to be welcomed that the governance of NFPs is beginning to receive greater scrutiny due to concerns about the function of boards. For example, Viader and Espina (2014, p.9), who investigated governance meetings, have found 'The most frequent board meeting agenda topic was evaluation and decision making regarding the organization's financial status, followed by the evaluation and approval of the top executive's operation's report'. Debates about purpose, based on an understanding of services and the manner in which they are delivered (or not), and attention to the organisational processes that support service delivery, are seemingly much lower on most boards' agendas.

Research also continues to show that appointments to governance boards are largely achieved through social networks (Cornish, 2013; Vidovich \& Currie, 2012), with appointments to large organisations still going predominantly to men in spite of pressures to have equal representation of men and women. Morris (2013), who investigated the representation of women, found that though women make up by far the greatest proportion of the workforce of the NFP sector, they continue to be grossly under-represented on boards. Concerns about the translation of governance to the ground on which staff and clients 'walk' are exacerbated when a patriarchal culture pervades, the leadership provided by boards is poor, CEOs and executive staff focus on the exertion of power over those in their employ, and when principles of humanity and social justice - or a passion for the work - are superseded by strategies to attain financial 
bottom lines. And to exacerbate matters, it is the Human Resources Management (HRM) group in the organisation that bears the brunt of reactions to decisions related to employment of staff. Ridder, Peining, and Baluch (2012) assert that HRM processes typically reflect 'values stemming from the labor movement [which] remain disconnected from the organization's goals' (p. 621). It may also be that employment legislation and structural arrangements are translated via managerialist approaches in a manner that leads to pressure to 'become more efficient and reduce costs ... thereby leading the organization to consciously violate values in their HR practices' (Ridder et al., 2012, p.621).

Supervision of professional staff is presenting its own set of concerns (Abramovitz \& Zelnick, 2015; King, Carson, \& Papatraianou, 2013) as performance measures are more likely to give priority to meeting targets and accounting for these via client information systems, rather than focusing on developing expertise or creative responses to resolving client disadvantage. Increasingly, too, employment takes the form of contracts tied to funding arrangements, is part time and casual in the name of flexibility, often to the employee's disadvantage (Abramovitz \& Zelnick, 2015). Compounding the clients' disadvantage is the amount of time now required for documentation and accountability processes, often needed to satisfy client information systems that are necessarily limiting in terms of the information they offer for service development (Gillingham \& Graham, 2015).

Finally, it is clear that the culture and leadership style developed in an organisation transmits throughout the organisation (Boddy, 2014). This means that coercive and bullying behaviours, disregard for the creativity of professional staff, and other undesirable behaviours are also transmitted through the hierarchy, as though a kind of permission is given for 'bad' behaviour - the shadow side of organisational life (Ket de Vries, 2004). This brings me to the second part of this commentary, and here I acknowledge that I will set aside the many achievements and positive outcomes of people's efforts in order to focus on what isn't working well.

The NFP sector has certainly experienced its share of bad behaviour over the decades with cases of abuse of clients, particularly children, doing significant damage to the sector's reputation. However, the introduction of managerial approaches is not without its own negative impacts on professional staff and their clients. The rise of management as a profession in its own right - one that privileges the knowledge base pertaining to commercial, for profit sector processes - has, at times, shown an almost complete disregard for the history, culture, purpose and fundamentally different values that drive the NFP world (Smyth, 2014). I suspect those who work in the health, welfare and education sectors will have observed any amount of bad behaviour associated with managerialist and managers' personal agendas being played out. My own experiences have allowed me to observe the impacts of mergers and to hear from those af- fected by the management approaches used. One man, who had worked hard to support a merger of health services was, without notice, made redundant. He was told he was no longer required and to pack his office and leave by the end of the week. More demeaningly, he was required to tell the staff team of his redundancy, without any form of support and with no clear explanation for the decision to give them. The result was an almost palpable atmosphere of insecurity within the agency. Downsizing in large organisations has also resulted in people who were 'unpopular' with a manager, or alleged to be 'under-performing', being summarily dispensed with, sometimes receiving this news via email, and during periods when they are unable to make contact with the purveyor of the information for days on end.

While not an everyday occurrence, these practices are not uncommon and most of us can recall, almost instantly, examples of similar behaviours. Even in the most recent of times, I learned of a manager terminating a staff member's contract in the hearing of other staff, I was made aware of inequalities maintained in contract rates of payment, and I was told of the withdrawal of an offer associated with a redundancy payout because the employee was unwilling to sign papers before their legality was checked. At other times, I have observed CEOs spending funds on favoured projects while creating deficits that pressured funded programmes against the advice of staff, and both direct and indirect pressure on employees to do overtime and carry high workloads over long periods without additional payment. I have also witnessed CEO and governance decision-making that lacked genuine interest in the concerns of professional staff, agency supporters or, indeed, of clients, in spite of those decisions having direct impacts on both the professional staff and clients of the organisation. And just in the last year, I received, in writing, a patronising and dismissive response from the chair of a board after expressing concern about management behaviour.

In the past, genuine interest on the part of executive staff and members of governance groups was a strong feature of the psychological contract with NFP staff. For staff, it provided a feeling of being well served even when the remuneration they received was known to be much lower than that of their colleagues in the public or commercial sectors (McDermott, Heffernan, \& Beynon, 2013). However, with changes to the functioning of NFP agencies, regular alterations to organisational structures (based on what is loosely referred to as 'strategic planning' (French, 2009)) and the need to market, brand or re-brand services (Amujo \& Laninhun, 2013), it is no wonder that I, along with others, have grown more sceptical about the benefits of these processes for staff and clients, especially given the time and money scarce resources in the NFP sector - taken up by such activities. While staff consultations and team building are part of the lexicon of management, they appear to be rather more often connected to managers' imperatives and to structural changes that have already been tacitly decided upon. 
There is now a body of research addressing the ethical and behavioural problems of management and managers, including the work of Manfred Ket de Vries whose interest lies in the shadow behaviours of managers and organisations; and Clive Boddy, whose special interest is the psychopathology of managers in organisations (Boddy, 2014, 2015). Their findings give considerable cause for unease. Rhode and Packel (2009) also address unethical behaviours in the NFP sector. Writing on the situation in America, they state:

In the 2007, National Nonprofit Ethics Survey, slightly more than half of employees had observed at least one act of misconduct in the previous year, roughly the same percentages as in the for-profit and government sectors. Nearly $40 \%$ of nonprofit employees who observed misconduct failed to report it, largely because they believed that reporting would not lead to corrective action or they feared retaliation from management or peers (Rhode \& Packel, 2009, p. 30).

In their summary of the research in this area, Rhodes and Packel (2009) identify 'four crucial factors that influence ethical conduct:

- Moral awareness: recognition that a situation raises ethical issues.

- Moral decision making: determining what course of action is ethically sound.

- Moral intent: identifying which values should take priority in the decision.

- Moral action: following through on ethical decisions' (p. 30).

The 'moral' aspects of decision making are, however, often absent, and the fear of retaliation felt by those who challenge decisions or openly disagree with managers is particularly worrying. Such conflicts may be experienced as a psychological breach of contract by employees leading to the diminishment of organisational loyalty and commitment (McDermott, et al., 2013). Managers' lack of consideration for the differing perspectives of staff can also limit the options put forward for service provision and development. It has been alarming to observe, too, that the disclosure of information by employees concerned about unethical behaviours - whistle-blowing - is frequently met with a closing of organisational ranks and responses that are contrived to discredit the complainant and divert attention from what is really going on. Given the nature of the sector in which they choose to operate, it is interesting that the executive management and members of governance boards seem unable to openly acknowledge the different points of view that will inevitably prevail, let alone admit to wrongdoing when challenged, or reflect on the underlying value differences that often exist. It is not so surprising, perhaps, that one study, carried out in Romania, found that managers were primarily 'preoccupied with 'ethical image' (Richea, 2013, p. 797) as opposed to behaving ethically, as this may ac- count for the slippage between espoused ethical values of an organisation and the (lack of) ethics that underpin some management actions.

This brings me to comment on the impacts of undesirable behaviours generated through governance and executive management. Already I have touched on the potential for organisational cultures to develop that fail to fit with the traditional and expected NFP values, ethics and moral stance. For employees, poor governance and management, together with the systemic impacts now experienced in this sector, the effects are concerning. They may include a lack of commitment to the organisation, lack of a sense of long-term purpose for working with clients, low interest in programme development and creative approaches to client work, higher levels of anxiety that will inevitably affect the quality of the work with clients, conflicts that are unable to be resolved and may result in the loss of professional expertise from the sector, and indirect effects on the families of employees. This is quite apart from the personal toll and the potential for emotional, psychological and physical impacts as a result of working in a stressful environment. As 'professional' as most welfare professionals aim to be, professionalism is always affected when redundancy threatens, when another job must be sought, when there are financial disincentives to continue in a position, and when governance, leadership and management behaviours are undermining.

What should be of concern to management and governing boards, and which many seem to overlook, is the passage of information between professional staff that reduces the interest in supporting, or working for, an organisation known for bad behaviours. As the saying puts it, 'What goes around, comes around'. Bad behaviour will inevitably affect funding, albeit indirectly as the professional grapevine begins to influence those beyond the immediate staff cohort. In recent times, I have observed at least one agency finally close as a result of bad management of finances and its staff, while others have had to 'merge' with more stable entities. Similarly, in the education sector, the effects of the grapevine were seen when community members began asking whether it was worth applying for regionally based courses, following major redundancies at La Trobe University in 2014/15. A major concern was that student numbers would drop, further reducing the financial wellbeing of the institution. Overcoming community concern entailed considerable PR efforts - and costs - while, in the background, staff who were made redundant abandoned their commitment to the institution and tried to find alternative employment.

For clients, the impacts of organisational management and governance might seem remote, but the nature of client relationships with professional and administrative staff will inevitably be affected by the factors of high staff turnover, high levels of anxiety due to conflict or concerns about employment status, less commitment to the work being undertaken, a lack of long-term focus, and the misuse of power that stems from a bullying or unethical culture of 
practices. In a context where clients rarely have much choice about where to access services, and little control over who they are allocated to for the delivery of services, the chances of achieving a sense of wellbeing and receiving holistic care may be significantly compromised.

Having expressed my anxieties about the immoderate aspects of governance and management in our sector and its influences on us and our work with clients, I return to the call for moderation - moderation accompanied by reflection and respectful consideration for the wellbeing of all employees in human service agencies, and their clients. This includes moderating the expression and use of power, taking a conciliatory approach when there are differences of perspective and perhaps being less captured by the managerialist and business culture and its constructed imperatives. There are, of course, many benefits to be gained from the changes we have experienced over the last 20 years, but it is a more balanced approach by personnel at all levels in the organisation - one that gives greater emphasis to the wellbeing of staff on the ground and the clients being served - that will lead to more positive narratives than those reflected in this editorial. We need to encourage new professionals to our ranks and ensure they are afforded the challenges, excitement and opportunities that many of us have enjoyed in more moderate times.

After a series of themed and special issues, we return in 2016 with an interesting compilation of papers encompassing a range of topics. This Issue begins with a typology of child homicide developed by Dean Biron and Danielle Reynald. Having recognised that discrepancies exist in the classification of child homicide, and that there have been significant changes in the field since the last major typology was developed, Dean and Danielle have developed an updated typology. This incorporates the developmental stages of the child, a set of classifications that are neither too specific nor too imprecise, and is relevant to specific cases as well as general research and policy development. The authors anticipate that this typology will help with identifying and preventing child homicide and other forms of child maltreatment.

The second paper by Gloria Lee and her colleagues from the United States reflects a study in which the authors talked with young people with a disability about their experiences of an inclusive therapeutic recreational camp. The young people interviewed said they experienced positive personal growth and gained new skills during the time spent at the camp. On the whole, participants benefited from the 'spirit of inclusion' and experienced social, psychological and practical benefits from the camp experience.

Anna Targowska, Tara Cavazzi and Stephen Lund examined the experiences of foster parents' biological children. Having spoken with service providers, foster parents and their biological children, they recommend that the foster care process take better account of the rights of biological children and that strategies that better meet their needs are implemented. The authors advocate the inclusion of developmentally appropriate training, improved information and support, as well as periods of respite for biological children.

Rose McCrickard and Catherine Flynn discuss the important issue of children's experiences at school when a parent has been arrested and incarcerated. According to the participants of this study, children's academic performance, behaviour and overall wellbeing are affected by their experiences of parental incarceration. They suggest that schools are well positioned to help mediate some of the detrimental impact, and are more likely to respond appropriately and positively to these children and their families when they are adequately informed of parental imprisonment.

A second school-based investigation reports on an evaluation of an early intervention programme called Got It!. Debbie Plath, Penny Crofts and Graeme Stuart found that the school-based specialised group intervention was successful at encouraging and assisting families with managing emerging child behavioural difficulties, and was particularly helpful with engaging parents who said they would not have otherwise pursued help.

Finally, there are two papers that address issues important to young people leaving out-of-home care. In the first of these, Adina Rahamim and Philip Mendes sought the views of agencies that provide support to young people leaving care, with a focus on the services required for good mental health during the transitional period. In accordance with earlier findings, the authors found that young people's mental health can be compromised by their experiences before care, during care and, importantly, during the transition from care. Because the transition from care can be a particularly stressful period, it places great strain on young people's mental health and can often exacerbate existing conditions. To help facilitate a smooth and successful transition, the authors advocate for not only improved services, but an extension of support through to the age of at least 21 years.

In a second article entitled Young people with complex needs leaving out-of-home care: Service issues and the need to enhance practice and policy, Catia Malvaso and Paul Delfabbro talk about the difficulties experienced by young people when leaving out-of-home care and how it can be even more challenging for young people who experience a disability, mental health concern, and those who disengage from services. Like the previous article, these authors spoke with service providers about their views on young people's preparedness for leaving care and the current services available to them. Participants identified limitations in services and eligibility, but also identified areas for improvement in policy/legislation, service delivery and individual practice.

This Issue concludes with two book reviews. Jennifer Lehmann shares her thoughts on the book written by Janet Taylor called Life chances: Stories of growing up in Australia, and Lesley-Anne Ey has provided a thorough review of the book Children's wellbeing in the media age with Handsley, 
MacDougall and Rich as editors. We hope that you find this to be an informative, useful and enjoyable issue of Children Australia.

\section{REFERENCES}

Abramovitz, M., \& Zelnick, J. (2015). Privatization in the human services: Implications for direct practice. Clinical Social Work, 43, 283-293. doi: 10.1007/s10615-015-0546-1.

Amujo, C., \& Laninhun, B. (2013). Organisational brand identity management: A critical asset for sustainable competitive advantage by non-profits. Third Sector Review, 19(1), 97-126.

Anheier, H., \& Kriev, G. (2014). Welfare regimes, policy reforms, and hybridity. American Behavioral Scientist, 58(1), 1395-1411.

Bish, A., \& Becker, K. (2015). Exploring expectations of nonprofit management capabilities. Nonprofit and Voluntary Sector Quarterly, [Online First], 1-21, doi: 10.1177/0899764015583313.

Boddy, C. (2014). Corporate psychopaths, conflict, employee affective well-being and counterproductive work behaviour. Journal of Business Ethics, 121(1), 107-121. doi: 10.1007/s10551-013-1688-0.

Boddy, C. (2015). Organisational psychopaths: A ten year update. Management Decision, 53(10), 2407-2432.

Carey, G., \& Riley, T. (2012). Fair and just or just fair? Examining models of government-not-for-profit engagement under the Australian Social Inclusion Agenda. Health Education Research, 27(4), 691-703.

Community Council for Australia (2014). Owning our future. Series 1: Better using our assets. Barton, ACT: Author. Retrieved from http://communitycouncil.com.au/sites/ default/files/CCA-Owining-Our-Future-Series-1-BetterUsing-Our-Assets-WEB.pdf

Considine, M., O’Sullivan, S., \& Nguyen, P. (2014). Mission drift?: The third sector and the pressure to be businesslike: Evidence from job services Australia. Third Sector Review, 20(1), 87-107.

Cornish, M. (2013). Exploring social networks of nonexecutive directors in Australian third sector organisations. Third Sector Review, 19(1), 51-73.

Coule, T. (2013). Nonprofit governance and accountability: Broadening the theoretical perspective. Nonprofit and Voluntary Sector Quarterly, 44(1) 75-97. doi: $10.1177 / 0899764013503906$.

French, S. (2009). Critiquing the language of strategic management. Journal of Management Development, 28(1), 6-17.

Gillingham, P., \& Graham, T. (2015). Designing electronic information systems for the future: Social workers and the challenge of the new public management. Critical Social Policy, 1-18, doi: 10.1177/0261018315620867.

Green, J. (2012). Grasping the nettle: Espousing values in the value plural operating context of not-for-profit social services. Procedia- Social and Behavioral Science, 58, 11491157.
Ket de Vries, M. (2004). Organizations on the couch: A clinical perspective on organizational dynamics. European Management Journal, 22(2), 183-200, doi:10.1016/j.emj.2004.01.008.

King, S., Carson, E., \& Papatraianou, L. (2013). The networked human service practitioner: Autonomous and entrepreneurial. Third Sector Review, 19(2), 99-118.

Maier, F., Meyer, M., \& Steinbereithner, M. (2014). Nonprofit organizations becoming business-like: A systematic review, Nonprofit and Voluntary Sector Quarterly [Online First], 123 doi: 10.1177/0899764014561796.

McDermott, A., Heffernan, M., \& Beynon, M. (2013). When the nature of employment matters in the employment relationship: A cluster analysis of psychological contracts and organizational commitment in the non-profit sector. The International Journal of Human Resource Management, 24(7), 1490-1518, doi: 10.1080/09585192.2012.723635.

Morris, L. (2013). Female governance in human services community benefit organisations: Reality or illusion? Third Sector Review, 19(2), 135-155.

Morris, T., \& Ogden, S. (2011). Funder demands for quality management in the non-profit sector: Challenges and responses in a non-profit infrastructure network Public Money \& Management, 31(2), 96-106. doi: 10.1080/09540962.2011.560703

Rhode, D., \& Packel, A. (2009). Ethics and nonprofits. Stanford Social Innovation Review. Summer. Retrieved from http://ssir.org/images/articles/2009SU_Feature_Rhode_ Packel.pdf

Richardson, D., \& Denniss, R. (2014). Income and wealth inequality in Australia. Policy Brief No. 64. Canberra: The Australia Institute. Retrieved from http://www.tai. org.au/sys Income and Wealth Inequality in Australia. Policy Brief No. 64 Canberra: The Australia Institutetem/files_force/PB+64+Income+and+wealth+ inequality+FINAL.pdf

Richea, M.-M. (2013). Management ethical principles and ethical behaviour in the non-profit organisations: Shaping a causal liaison or a myth? Procedia: Social and Behavioural Science, 92, 789-798.

Ridder, H., Piening, E., \& Baluch, A. (2012). The third way reconfigured: How and why nonprofit organizations are shifting their human resource management. Voluntas, 23(3), 605-635.

Saj, P. (2013). Managing multiple accountabilities: Balancing outputs, inputs, and behaviours to implement strategy in a large Australian charity. Third Sector Review, 19(2), 51-78.

Smith, S. (2015). Managing human service organizations in the 21st Century. Human Service Organizations: Management, Leadership \& Governance, 39(5), 407-411. doi: 10.1080/23303131.2015.1087783.

Smyth, P. (2014). As our voluntary sector vanishes, we mustn't just wave it goodbye. The Conversation. Retrieved from http://theconversation.com/as-our-voluntary-sectorvanishes-we-mustnt-just-wave-it-goodbye-30476.

The Australian Ballet (2015). Talking pointe. The newsletter for patrons. December. Melbourne: Author. 
Viader, A., \& Espina, M. (2014). Are not-for-profits learning from for-profit-organizations? A look into governance. Corporate Governance, 14(1), 1-14.

Vidovich, L., \& Currie, J. (2012). Governance networks interlocking directorships of corporate and nonprofit boards.
Nonprofit Management and Leadership, 22(4), 507-523. doi: 10.1002/nml.21042.

Wagner, A. (2014). Good governance: A radical and normative approach to non-profit management. Voluntas, 25(3), 797817. 